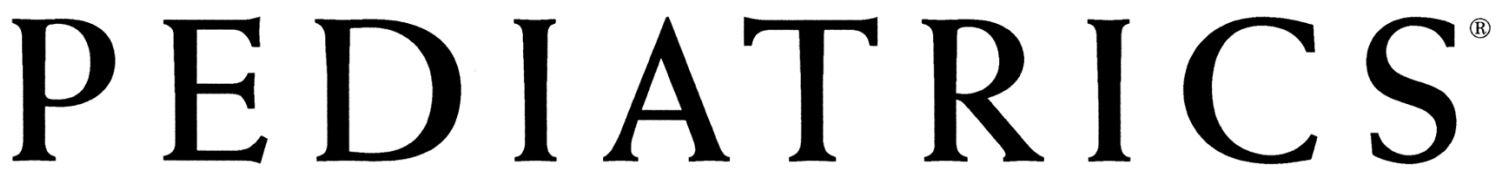

OFFICIAL JOURNAL OF THE AMERICAN ACADEMY OF PEDIATRICS

\title{
Constipation as the Presenting Symptom in De Novo Multiple Endocrine
} Neoplasia Type 2B

Ronald R. de Krijger, Alice Brooks, Erwin van der Harst, Robert M. W. Hofstra, Hajo

A. Bruining, Jan C. Molenaar and Carel Meijers

Pediatrics 1998;102;405-407

DOI: $10.1542 /$ peds.102.2.405

This information is current as of December 11, 2006

The online version of this article, along with updated information and services, is located on the World Wide Web at:

http://www.pediatrics.org/cgi/content/full/102/2/405

PEDIATRICS is the official journal of the American Academy of Pediatrics. A monthly publication, it has been published continuously since 1948. PEDIATRICS is owned, published, and trademarked by the American Academy of Pediatrics, 141 Northwest Point Boulevard, Elk Grove Village, Illinois, 60007. Copyright (@ 1998 by the American Academy of Pediatrics. All rights reserved. Print ISSN: 0031-4005. Online ISSN: 1098-4275.

\section{American Academy of Pediatrics}


9. Keilty SR, Bridges JM. Ketamine for minor procedures in children Lancet. 1972;1:631. Letter

10. Meadows AT, Mayer BW, Naiman JL. Ketamine for minor procedures in children. Lancet. 1972;1:631. Letter

11. Elliott E, Hanid TK, Arthur LJH, Kay B. Ketamine anaesthesia for medical procedures in children. Arch Dis Child. 1976;51:56-59

12. Wilson RD, Nichols RJ, McCoy NR. Dissociative anesthesia with CI-581 in burned children. Anesth Analg. 1967;46:719-724

13. Patt RB. Overview: prescribing relationship-a powerful intervention for pediatric pain. Pediatr Ann. 1995;24:123-124

14. Friedman AG, et al. Midazolam premedication for pediatric bone marrow aspiration and lumbar puncture. Med Pediatr Oncol. 1991;19: 499-504

\section{Constipation as the Presenting Symptom in De Novo Multiple Endocrine Neoplasia Type 2B}

ABBREVIATIONS. MEN 2, multiple endocrine neoplasia type 2; MTC, medullary thyroid carcinoma; PCR, polymerase chain reaction; IND B, intestinal neuronal dysplasia type B.

$\mathrm{M}$ ultiple endocrine neoplasia type 2 (MEN 2) comprises three clinically distinct dominantly inherited neuroendocrine cancer syndromes: MEN 2A, MEN 2B, and familial medullary thyroid carcinoma, which share medullary thyroid carcinoma (MTC) as part of the disease spectrum. ${ }^{1}$ MEN 2A patients are characterized by the additional occurrence of pheochromocytoma and/or parathyroid hyperplasia. MEN 2B patients also have pheochromocytomas and, very rarely, parathyroid hyperplasia; in addition, they have mucosal neuromas, mainly of the buccal mucosa and tongue, ganglioneuromatosis of the gastrointestinal tract, skeletal and ophthalmologic abnormalities, and a Marfanoid habitus $^{2}$ (Table 1). All MEN 2 syndromes are caused by missense mutations in different areas of the RET proto-oncogene, ${ }^{3-5}$ which encodes a receptor tyrosine kinase, for which glial cell-line derived neurotrophic factor and neurturin are the ligands. ${ }^{6-8}$ A single, identical point mutation in the catalytic core of the RET tyrosine kinase domain (codon $918^{\mathrm{Met} \rightarrow \mathrm{Thr}}$ ) has been found in $94 \%$ of inherited and de novo cases of MEN 2B, which makes this disorder well-suited for genetic testing. ${ }^{9}$ Because of this and because $50 \%$ of MEN 2B cases present de novo, it is important to be aware of possible presenting symptoms in combination with the typical features of MEN 2B patients. Very rarely, patients with typical MEN 2B features do not have RET codon 918 (exon 16) mutations. $^{9-11}$ Those cases are most probably caused by mutations elsewhere in the RET gene, eg, at codon 883 of RET exon $15 .^{12}$

In this report, we present a case of a girl with

Received for publication Dec 9, 1997; accepted Feb 13, 1998.

Address all correspondence and reprint requests to: Ronald R. de Krijger, MD, PhD, Department of Pathology, Erasmus University, PO Box 1738, 3000 DR Rotterdam, The Netherlands.

PEDIATRICS (ISSN 0031 4005). Copyright @ 1998 by the American Academy of Pediatrics.
TABLE 1. Features of MEN 2B

Facial abnormalities

Thickened and everted upper eyelids

Prominent eyebrows

Neuromas on eyelids and conjunctiva

Thickened corneal nerves

Elongated face

Thickened lips

Neuromas of buccal mucosa, tongue, and palate

Marfanoid habitus/musculoskeletal manifestations

Tall stature

High-arched palate

Long extremities

Kyphoscoliosis or lordosis

Joint laxity

Pes cavus

Pectus excavatum

Slipped capital femoral epiphysis

Gastrointestinal manifestations

Abdominal distension

Feeding problems

Dysphagia

Vomiting

Chronic constipation

Paradoxal diarrhea

Megacolon

Ganglioneuromatosis

Tumors

C-cell hyperplasia/medullary thyroid carcinoma

Pheochromocytoma

Parathyroid hyperplasia

dysmorphic features, chronic constipation, and abnormal histology of the enteric nervous system in early childhood. Sixteen years later, she presented with MTC and was found to harbor a de novo RET mutation, characteristic of MEN 2B.

\section{MATERIALS AND METHODS}

\section{Histology and Immunohistochemistry}

Five-micron sections of paraffin-embedded tissue (resected colon and MTC) were deparaffinized. Hematoxylin and eosin and sirius red staining (colon) were performed according to standard methods. For immunohistochemistry, sections were incubated for 30 minutes at room temperature with antibodies to calcitonin (1:900, Dako, Glostrup, Denmark) and thyroglobulin (1:2500, Dako) for the MTC, and PGP9.5 (1:1000, Biogenesis, New Fields, UK) and S100 (1:2500, Dako) for the colon. A microwave antigen retrieval method was used followed by overnight incubation at $4^{\circ} \mathrm{C}$ for antibodies to RET (1:3000, Dako), for the MTC. Then, sections were washed and a biotinylated goat-anti-multilink (1:50, Klinipath Biogenex, Uden, The Netherlands) with $2 \%$ normal human serum and $2 \%$ normal goat serum (Dako) was added for 30 minutes, followed by the avidin-biotin-complex (1:50, Klinipath Biogenex) for 30 minutes. Sections were developed with diaminobenzidine tetrahydrochlorate (Fluka, Neu-Ulm, Germany) with $0.3 \% \mathrm{H}_{2} \mathrm{O}_{2}$ for 7 minutes, counterstained, dehydrated, and mounted.

\section{Mutational Analysis}

Lymphocyte DNA was isolated according to standard procedures from the index patient, from both parents, and from both siblings. Polymerase chain reaction (PCR) was carried out as previously described. ${ }^{5}$ The PCR products were purified in low-melting point agarose, isolated (Sephaglas BandPrep kit, Pharmacia, Uppsala, Sweden) and digested for 1 hour using 2U FokI (Boehringer, Mannheim, Germany) in the restriction buffer recommended by the manufacturer. The samples were run in a $1 \%$ normal agarose $/ 2 \%$ low-melting point agarose gel.

\section{CASE REPORT}

A 2-year-old child of nonconsanguineous parents came to medical attention because of severe growth retardation without 
catch-up growth and presumed psychomotor retardation, which was not proven at subsequent analysis. At physical examination she was growth-retarded (length well below P3) and presented with dysmorphic features including hypertelorism, a broad forehead and mouth, a short neck, high-arched palate, and pectus excavatus. Radiography of the skeleton revealed vertebral abnormalities: occipitalization of $\mathrm{C} 1$, a hypoplastic $\mathrm{C} 2$, block vertebrae C2 and C3, and scoliosis. Skeletal age was delayed.

During evaluation she was found to have severe chronic constipation and paradoxal diarrhea. Radiographically, the transverse colon was dilated, the splenic flexure seemed stenotic, and the distal colon was collapsed. Because Hirschsprung disease was suspected, a biopsy was taken that showed the same histologic features as the later bowel resection (see below). At subsequent laparotomy the radiographic findings were confirmed but no stenosis could be located. The splenic flexure was removed for pathologic examination. There was an increase in the number of ganglion cells, both in the submucous and myenteric plexus as well as an increase in nerve fibers in submucosa and mucosa, part of which were acetylcholinesterase-reactive. The ganglion cells were of normal size, but there were no ectopic ganglion cells in the lamina propria or muscularis mucosae. As aganglionosis of the distal colon had been excluded, continuity was restored. The initial pathologic diagnosis was intestinal neuronal dysplasia of the colon. At review, many years later, this was changed to ganglioneuromatosis (Fig 1).

In subsequent years she was seen for the analysis of persistent diarrhea and because of neurogenic bladder dysfunction and ureteral reflux. At the age of 18 years a swelling of the thyroid region was noted, and during physical examination prominent lips and tongue neuromas were noticed for the first time. Around that time DNA analysis for RET mutations was performed for both parents and the three children. A codon 918 (exon 16) mutation was found in the index patient, but not in the DNA of parents and siblings (Fig 2). Subsequent investigations revealed an unevenly enlarged thyroid with calcifications, tracheal compression, and markedly elevated serum calcitonin, carcinoembryonic antigen, and CA125. A total thyroidectomy was performed, and MTC was found in the resected gland (Fig 3). A single metastasis was present in a regional lymph node. Calcitonin and carcino-embryonic antigen levels returned to control levels after the operation. Recently, 2 years postoperatively, she was found to have a positive somatostatin scan in the neck and mediastinal region and a raised calcitonin level was found after pentagastrin stimulation, both indicating that MTC metastasis may be present. Cytology of neck lymph node was consistent with MTC metastasis.

Before and after thyroidectomy, urinary vanillylmandelic acid excretion was repeatedly around the upper limit of normal, but the meta-iodobenzylguanidine scan did not show increased uptake in the adrenals. Furthermore, glucagon provocation showed a normal response. At present, there is no indication for the presence of a pheochromocytoma.

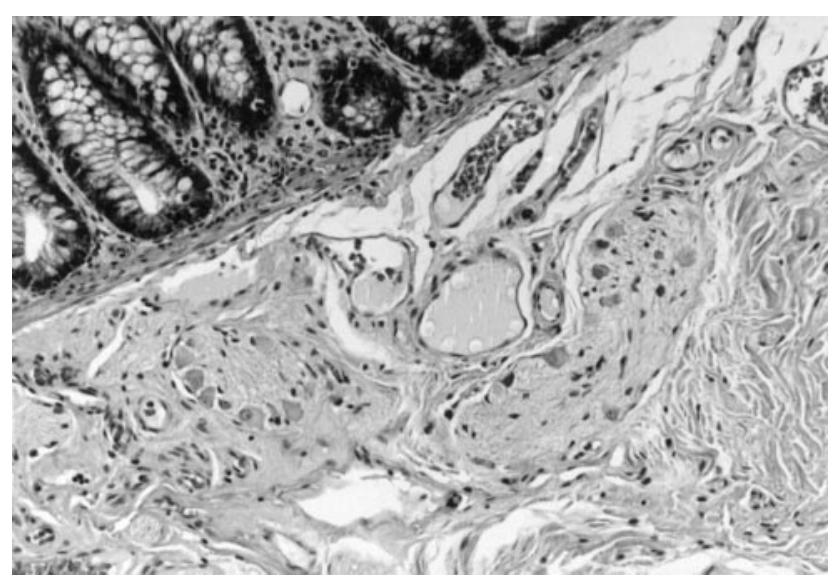

Fig 1. Resected colon segment showing the hyperplasia of the submucous plexus with multiple ganglion cells and broad nerve fibers, typical of ganglioneuromatosis (hematoxylin-eosin, $\times 40$ ).

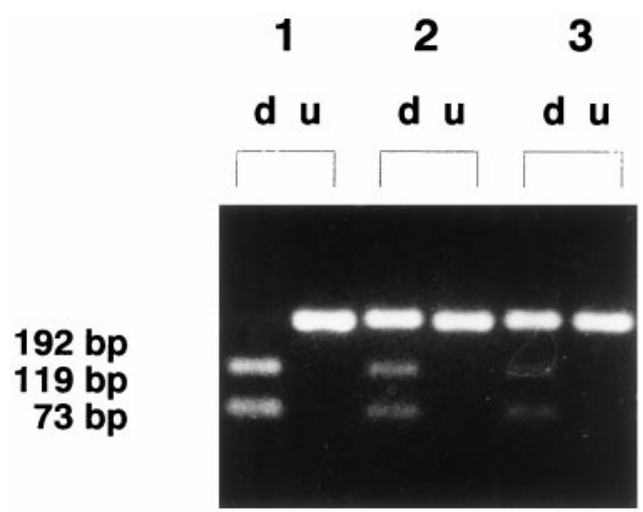

Fig 2. Restriction patterns of PCR products of exon 16 of RET with FokI. The MEN 2B mutation $(\mathrm{T} 2753 \rightarrow$ C) eliminates a FokI restriction site. The undigested $(\mathrm{u})$ and the digested (d) PCR products of constitutive DNA from a control individual (No. 1), from the index patient (No. 2) and from a known MEN 2B patient (No. 3) are shown. The index patient and the MEN 2B patient show the same digestion pattern, caused by the same mutation.

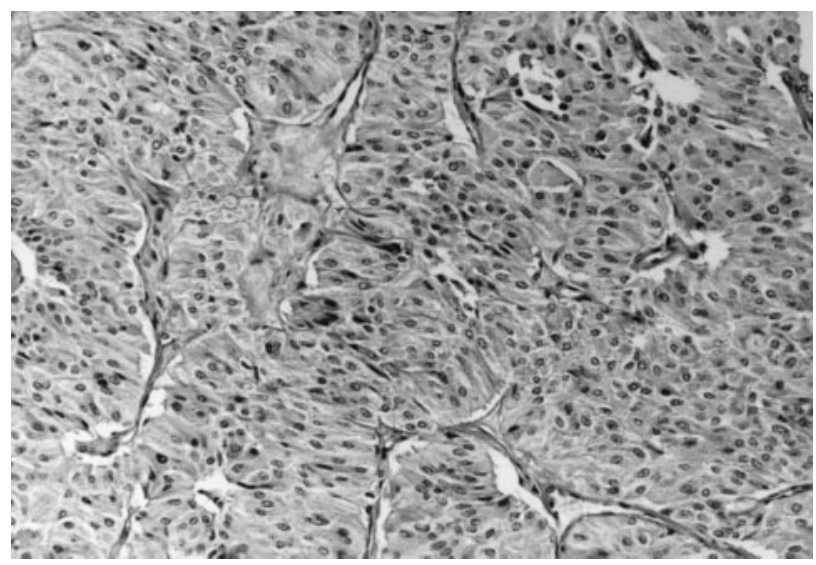

Fig 3. Medullary thyroid carcinoma with a solid proliferation or round to polygonal cells with granular amphophilic cytoplasm with medium-sized nuclei. Between the tumor cells is highly vascularized stroma with collagen bands and amyloid depositions (hematoxylin-eosin, $\times 40$ ).

\section{DISCUSSION}

This patient with a de novo RET codon $918^{\mathrm{Met} \rightarrow \mathrm{Thr}}$ mutation, leading to the MEN 2B syndrome, originally presented with chronic constipation, paradoxal diarrhea, and histologic abnormalities of the enteric nervous system in rectal and colonic biopsies. MEN $2 \mathrm{~B}$ is a rare autosomal dominant disorder of which MTC is the most serious and potentially lethal complication. MTCs in MEN 2B are known to run an aggressive course, as compared with MTCs in MEN 2A, and metastatic MTCs may be found in children younger than age $5 .^{13}$ This may be related to the site of the RET mutation, as sporadic MTCs with an identical RET codon 918 mutation also follow an aggressive clinical course with earlier tumor recurrence, higher frequency of metastases, and decreased survival rate. ${ }^{14-16}$ Early detection of individuals at risk for MEN 2B allows prophylactic thyroidectomy to be carried out before metastatic disease occurs. ${ }^{17-19}$ This screening, however, is hampered by the fact that at least $50 \%$ of MEN 2B cases represent de novo mutations..$^{20}$ For such patients, presenting symptoms 
should lead to clinical suspicion prompting genetic testing.

Many studies have indicated the early occurrence of clinical gastrointestinal symptoms in MEN 2B patients, including difficulty in feeding, dysphagia, vomiting, constipation, diarrhea, borborygmus, intermittent abdominal pain, and occasional malabsorption. ${ }^{21-24}$ Of these, chronic constipation and diarrhea are the most commonly observed. However, such clinical symptoms are common in the general pediatric age group, with a multitude of etiologic and pathogenetic factors involved. Therefore, additional clinical data are required. In MEN 2B, several radiographic abnormalities may be found: disturbed motility and segmental dilatation of the esophagus, gastroesophageal reflux, distention of the stomach, segmental dilatation of the small bowel, abnormal haustral pattern of the colon, and megacolon, which is the most frequent abnormality. ${ }^{21,25}$ Although the differential diagnosis of megacolon includes many disorders (Table 1), Hirschsprung disease is usually suspected strongly.

Intestinal mucosal biopsy yields important information about the intestinal innervation pattern and allows the differentiation between Hirschsprung disease and ganglioneuromatosis. In Hirschsprung disease a bowel segment of variable length is aganglionic and presents an increase in cholinergic nerve fibers. The neighboring bowel segment is hypoganglionic. Ganglioneuromatosis displays an increase in ganglion cells, supportive cells, and nerve fibers in all layers of the bowel wall, most notably in the myenteric plexus. ${ }^{26}$

Ganglioneuromatosis can involve the entire gastrointestinal tract. Recently, a case was presented with coexistence of ganglioneuromatosis, in the context of MEN 2B with its characteristic RET codon 918 mutation, and a short aganglionic segment, indicative of Hirschsprung disease. ${ }^{27}$ Intestinal neuronal dysplasia type B (IND B) has several features resembling ganglioneuromatosis, most importantly submucosal ganglia with more than six nerve cells. ${ }^{28}$ No mention is made about the myenteric plexus. Whether IND B represents an entity or a secondary phenomenon has been much debated, ${ }^{29}$ but is beyond the scope of this article.

In our patient, intestinal biopsy was performed after radiographic detection of a dilated proximal and a collapsed distal colonic segment. The innervational abnormalities were initially diagnosed as IND B. At that time, almost 20 years ago, no facial abnormalities were noticed, except a high-arched palate. However, these abnormalities, most notably neuromas of the tongue, may be discrete in children and become more prominent in older individuals. As no genetic testing was available and the Marfanoid features (scoliosis, pectus excavatus, high-arched palate) were not appreciated, it was not until thyroid enlargement occurred that a diagnosis of MEN 2B was made. That the sign or symptom leading to the diagnosis was preceded by a different, at that time unrecognized, sign or symptom seems characteristic of this syndrome. ${ }^{24}$ It is unclear whether the remaining congenital dysmorphic features (broad forehead and mouth, short neck, and vertebral anomalies) and the neurogenic bladder dysfunction are coincidental or related to the MEN 2B phenotype.

\section{CONCLUSION}

Our case shows that MEN 2B should be in the differential diagnosis of chronic constipation in young children, especially if additional clinical, radiographic, or pathologic findings are indicative of MEN 2B. In general, mutational analysis of the RET proto-oncogene is strongly recommended in cases of histologically abnormal biopsies showing innervational maldevelopment and in children with one or more other features of the MEN 2B syndrome, including medullary or adrenal tumors (Table 1). This may lead to (prophylactic) thyroidectomy and/or prevention of metastatic MTC. Once a diagnosis is established, genetic counseling should also be offered to other at-risk family members to ascertain their mutational status.

\author{
Ronald R. De Krijger, MD, PhD* \\ Alice Brooks, MD \\ ERWIN VAN DER HARST, MD§ \\ Robert M. W. Hofstra, PhDII \\ Hajo A. Bruining, MD, PhD§ \\ Jan C. MolenaAr, MD, PhD\| \\ Carel Meijers, MD, PhD\| \\ Departments of *Pathology, †Clinical Genetics, \\ $\S$ Surgery and $\|$ Pediatric Surgery \\ University Hospital Dijkzigt, Rotterdam \\ IIDepartment of Medical Genetics \\ State University \\ Groningen, The Netherlands
}

\section{ACKNOWLEDGMENTS}

This work was supported by the Sophia Foundation for Scientific Research and by the Foundation of Clinical Genetics.

We thank P. Komminoth and W. J. Mooi for critically reading the manuscript, W. A. Meier-Ruge and P. J. Milla for revising the original colonic biopsies, and F. van der Ham for expert technical assistance.

\section{REFERENCES}

1. Ponder BAJ, Smith D. The MEN II syndromes and the role of the RET proto-oncogene. Adv Cancer Res. 1996;70:179-222

2. Schimke RN, Hartmann WH, Prout TE, Rimoin TL. Syndrome of bilateral pheochromocytoma, medullary thyroid carcinoma and multiple neuromas. N Engl J Med. 1968;279:1-7

3. Donis-Keller H, Dou S, Chi D, et al. Mutations in the RET protooncogene are associated with MEN 2A and FMTC. Hum Mol Genet. 1993;2:851-856

4. Eng C, Smith DP, Mulligan LM, et al. A novel point mutation in the tyrosine kinase domain of the RET proto-oncogene in sporadic medullary thyroid carcinoma and in a family with FMTC. Oncogene. 1995;10: $509-513$

5. Hofstra RMW, Landsvater RM, Ceccherini I, et al. A mutation in the RET proto-oncogene associated with multiple endocrine neoplasia type 2B and sporadic medullary thyroid carcinoma. Nature. 1994;367:375-376

6. Durbec P, Marcos-Gutierrez CV, Kilkenny C, et al. GDNF signalling through the RET receptor tyrosine kinase. Nature. 1996;381:789-793

7. Treanor JJS, Goodman L, de Sauvage F, et al. Characterization of a multicomponent receptor for GDNF. Nature. 1996;382:80-83

8. Heukeroth RO, Kotzbauer P, Copeland NG, et al. Neurturin, a novel neurotrophic factor, is localized to mouse chromosome 17 and human chromosome 19p13.3. Genomics. 1997;44:137-140

9. Eng C, Clayton D, Schuffenecker I, et al. The relationship between specific RET proto-oncogene mutations and disease phenotype in multiple endocrine neoplasia type 2: international RET mutation consortium analysis. JAMA. 1994;276:1575-1579

10. Toogood AA, Eng C, Smith DP. No mutation at codon 918 of the RET gene in a family with MEN type 2B. Clin Endocrinol. 1995;43:759-762 
11. Dennehy PJ, Feldman GL, Kambouris M, et al. Relationship of familial prominent corneal nerves and lesions of the tongue resembling neuromas to multiple endocrine neoplasia type 2B. Am J Ophthalmol. 1995; 120:456-461

12. Smith DP, Houghton C, Ponder BAJ. Germline mutation of RET codon 883 in two cases of de novo MEN 2B. Oncogene. 1997;15:1213-1217

13. Kaufman FR, Roe TF, Isaacs HJ, et al. Metastatic medullary thyroid carcinoma in young children with mucosal neuroma syndrome. Pediatrics. 1982;70:263-267

14. Zedenius J, Larsson C, Bergholm U, et al. Mutations of codon 918 in the RET proto-oncogene correlate to poor prognosis in sporadic medullary thyroid carcinomas. J Clin Endocrinol Metab. 1995;80:3088-3090

15. Romei C, Elisei R, Pinchera A, et al. Somatic mutations of the RET proto-oncogene in sporadic medullary thyroid carcinoma are not restricted to exon 16 and are associated with tumor recurrence. J Clin Endocrinol Metab. 1996;81:1619-1622

16. Komminoth P, Kunz EK, Matias-Guiu X, et al. Analysis of RET protooncogene point mutations allows for the discrimination of heritable and non-heritable medullary thyroid carcinoma. Cancer. 1995;76:479-489

17. Gill JR, Reyesmugica M, Iyengar S, et al. Early presentation of metastatic medullary thyroid carcinoma in multiple endocrine neoplasia, type IIA: implications for therapy. J Pediatr. 1996;129:459-464

18. Pacini F, Romei C, Miccoli P, et al. Early treatment of hereditary medullary thyroid carcinoma after attribution of multiple endocrine neoplasia type 2 gene carrier status by screening for RET gene mutations. Surgery. 1995;118:1031-1035

19. Lairmore TC, Frisella MM, Wells SA. Genetic testing and early thyroidectomy for inherited medullary thyroid carcinoma. Ann Med. 1996;28. 401-406

20. Carlson KM, Bracamontes J, Jackson CE, et al. Parent-of-origin in multiple endocrine neoplasia type 2B. Am J Hum Genet. 1994;55:1076-1082

21. Demos TC, Blonder J, Schey WL, Braithwaite SS, Goldstein PL. Multiple endocrine neoplasia (MEN) syndrome. Type IIB: gastrointestinal manifestations. AJR. 1983;140:73-78

22. Carney JA, Go VLW, Sizemore GW, Hayles AB. Alimentary-tract ganglioneuro-matosis. N Engl J Med. 1976;295:1287-1291

23. O'Riordain DS, O'Brien T, Crotty TB, Gharib H, Grant CS, van Heerden JA. Multiple endocrine neoplasia type 2B: more than an endocrine disorder. Surgery. 1995;118:936-942

24. Vasen HFA, van der Feltz M, Raue F, et al. The natural course of multiple endocrine neoplasia type IIb: a study of 18 cases. Arch Intern Med. 1992;152:1250-1252

25. Dunzendorfer T, Lee VW, Levine S, de las Morenas A, Beazley RM, Chipkin S. Refractory constipation and megacolon in MEN 2b. Dig Dis Sci. 1996;41:2233-2237

26. D'Amore ESG, Manivel JC, Pettinato G, Niehans GA, Snover DC. Intestinal ganglioneuromatosis: mucosal and transmural types. Hum Pathol. 1991;22:276-286

27. Verga U, Console D, Jasonni V, et al. An unusual co-existence: Hirschsprung disease and MEN 2B submucosal neurofibromatosis. Sixth International Workshop on Multiple Endocrine Neoplasia and Von Hippel-Lindau Disease; Noordwijkerhout; June 25-28, 1997; The Netherlands; page 149

28. Meier-Ruge WA, Brönnimann PB, Gambazzi F, Schmid PC, Schmidt CP, Stoss F. Histopathological criteria for intestinal neuronal dysplasia of the submucosal plexus (type B). Virchows Arch. 1995;426:549-556

29. Sacher P, Briner J, Hanimann B. Is neuronal intestinal dysplasia (NID) a primary disease or a secondary phenomenon? Eur J Pediatr Surg. 1993;3:228-230

\section{Abdominal Lipohypertrophy Caused by Injections of Growth Hormone: A Case Report}

ABBREVIATIONS. GH, growth hormone; IGF-I, insulin-like growth factor-I.

G rowth hormone $(\mathrm{GH})$ is administered by subcutaneous injections. Common complications have been limited to bruising, a development of a hematoma at the injection sites. ${ }^{1,2}$ However, local atrophy or dimpling and hypertrophy or lumps have been observed occasionally. The purpose of this report is to present a boy who developed significant hypertrophy of the subcutaneous tissue mass at the local site of GH injections in his abdomen.

\section{CASE REPORT}

J. T. was a 12.5-year-old healthy boy with short stature. Linear growth was noted to decline at 3 years of age. Since then, he continued to grow slow; in comparison with the growth observed on his older sibling and peers of the same age group (no documentation is available). At the time of presentation he was below two standards deviations from the mean. At the time of his birth the mother was 32 years old and his father was 48 years of age. The mother's stature was $160 \mathrm{~cm}$; the father's was $173 \mathrm{~cm}$. His 18-year-old brother weighed $3.2 \mathrm{~kg}$ at birth. His growth and development were normal and his stature was $168 \mathrm{~cm}$. There is no history of consanguinity, short stature, or delayed adolescence in the family. He was the $2.35-\mathrm{kg}, 48.5-\mathrm{cm}$ product of a term gestation. His mother was G2, P1, and suffers from epilepsy. Medications used during gestation included Tegretol, Mysoline, and Dyazide. The mother was diagnosed with preeclampsia at the last trimester. The birth was vaginal. Neonatorum was uneventful. Development milestones included the following: sitting up at 7 months, crawling at 10 months, walking at 19 months, talking at 24 months. In grammar school he required training in communication skills as well as physical therapy for coordination skills. He has been able to attend regular school programs, and he is an average student.

The physical examination revealed a well-nourished, healthy appearing boy. Stature was $132.2 \mathrm{~cm}$, weight was $27.1 \mathrm{~kg}$, head circumference was $52.5 \mathrm{~cm}$, arm span was $126 \mathrm{~cm}$, and the upper to lower ratio was 1.04 . (Normal for bone age 0.98 and for chronological age 0.95$).{ }^{3}$ Secondary sex characteristics were in Tanner's stage 1 , with a testicular volume of $2 \mathrm{~mL}$ laterally. The bone age was shown to be 10 years old as indicated by the Greulich and Pyle technique.

Laboratory data revealed: thyroid-stimulating hormone, 3.2 $\mathrm{miu} / \mathrm{Ml}(3.2 \mathrm{pmol} / \mathrm{L})$; thyroxine, $6.8 \mu \mathrm{g} / \mathrm{Dl}(87.5 \mathrm{nmol} / \mathrm{L})$. The insulin-like growth factor-I (IGF-I)-binding protein-3 was 2.2 $\mathrm{mg} / \mathrm{L}(0.05 \mathrm{nmol} / \mathrm{L})$. The L-Dopa stimulation test showed GH response levels of $9.9,6.9$, and $3.1 \mathrm{ng} / \mathrm{Ml}$ at 30,60, and 90 minutes, respectively $(\mathrm{nL}>10 \mathrm{ng} / \mathrm{Ml})$. The complete blood (cell) count, sedimentation rate, urinalysis, blood urea nitrogen, and serum electrolytes were all normal.

GH therapy (Protropin) at a dose of $0.05 \mathrm{mg} / \mathrm{kg} /$ day was initiated at 12.5 years of age. It was administered subcutaneous with a 29-gauge hypodermic needle. The skin was prepared with alcohol wipes. The linear growth and growth velocity are shown in Fig 1. The patient's growth velocity increased significantly during the GH therapy. Quarterly physical examinations revealed a progressive increment in abdominal volume that initially was thought to be a normal abdominal fat increment. At 15 years of age the configuration and isolated volume of the abdominal morphology was judged to be abnormal, consisting of two vertically elongated masses that measured $15 \times 12 \mathrm{~cm}$ located parallel to the middle line (Fig 2). The consistency was similar to the rest of the adjacent subcutaneous tissue and demarcated above the abdominal musculature. The child's parents stated that GH has been exclusively injected under the skin into the abdominal area for the previous years. The parents were instructed to avoid the abdomen for the site of injections and to use multiple rotation method. At the last examination ( 6 months later) there was $\sim 50 \%$ reduction in the volume of the fat pads. Pubertal development in Tanner's stage 2 was noted at 13 years of age; Tanner's stage 3 at 14 years of age; and Tanner's stage 4 at 15.5 years of age.

\section{DISCUSSION}

Studies of the lipid metabolism and number, size, and distribution of fat cell with $\mathrm{GH}$ administration

Received for publication Sep 22, 1997; accepted Mar 18, 1998.

Reprint requests to (R.H.A.R.) Rainier School, Box 600, Buckley, WA 98321. PEDIATRICS (ISSN 0031 4005). Copyright (C) 1998 by the American Academy of Pediatrics. 


\section{Constipation as the Presenting Symptom in De Novo Multiple Endocrine Neoplasia Type 2B}

Ronald R. de Krijger, Alice Brooks, Erwin van der Harst, Robert M. W. Hofstra, Hajo

A. Bruining, Jan C. Molenaar and Carel Meijers

Pediatrics 1998;102;405-407

DOI: $10.1542 /$ peds.102.2.405

This information is current as of December 11, 2006

\begin{tabular}{|ll|}
\hline $\begin{array}{l}\text { Updated Information } \\
\text { \& Services }\end{array}$ & including high-resolution figures, can be found at: \\
References & http://www.pediatrics.org/cgi/content/full/102/2/405 \\
& This article cites 26 articles, 7 of which you can access for free \\
at: & http://www.pediatrics.org/cgi/content/full/102/2/405\#BIBL \\
Citations & This article has been cited by 1 HighWire-hosted articles: \\
& http://www.pediatrics.org/cgi/content/full/102/2/405\#otherarticle \\
& $\mathrm{s}$ \\
Subspecialty Collections & This article, along with others on similar topics, appears in the \\
& following collection(s): \\
& $\begin{array}{l}\text { Endocrinology } \\
\text { http://www.pediatrics.org/cgi/collection/endocrinology } \\
\text { Information about reproducing this article in parts (figures, } \\
\text { tables) or in its entirety can be found online at: } \\
\text { http://www.pediatrics.org/misc/Permissions.shtml } \\
\text { Information about ordering reprints can be found online: } \\
\text { http://www.pediatrics.org/misc/reprints.shtml }\end{array}$ \\
&
\end{tabular}

